\title{
Effect of Palm Oil, Palm Olein, Palm Kernel Oil and Their Blends on the Lipid Profile of Albino Rats
}

\author{
1*IMOISI, OB; ${ }^{1}$ EZOGUAN, VO; ${ }^{2}$ IMAFIDON, MI \\ ${ }^{* 1}$ Biochemistry Division, Nigeria Institute for Oil Palm Research (NIFOR), Benin, Nigeria \\ ${ }^{2}$ Chemistry Department, University of Benin, Benin-City, Nigeria \\ *Corresponding Author Email: imoisib@gmail.com; Tel.: +2347031091212, +2347056812700
}

\begin{abstract}
Edible oils play an important role in the body as carriers of essential fatty acids, this essential fatty acids are not produced in the body but gotten from diet we consume. This study examined the effect of palm oil, palm olein, palm kernel oil and their blends (PKO: POL and POL: PKO) on the lipid profile of Albino rats. The aim was to investigate the nutritional and health effects of these oils. Serum was used in the biochemical analysis of lipid profile using Randox Laboratories (England) kit. High density lipoprotein cholesterol in rats fed diets containing unheated and unblended PKO was lower than the recommended range and palm olein and their blends were all higher than the recommended range of 40-59mg/dL. Palm kernel oil fortified diet significantly increased triglyceride levels while; total cholesterol levels were considered to be acceptable except for palm kernel oil and its blends. Palm kernel oil and higher blend of palm kernel oil increased significantly very low density lipoprotein cholesterol above the recommended limit of $2-30 \mathrm{mg} / \mathrm{dl}$. Low density lipoprotein cholesterol values in this study were far below the recommended limit for PKO and higher blends of PKO. In conclusion palm oil helps to lower total cholesterol concentration by stimulating the synthesis of protective HDL-C. Palm kernel oil increases total triglyceride and total cholesterol levels.
\end{abstract}

\section{DOI: https://dx.doi.org/10.4314/jasem.v25i8.21}

Copyright: Copyright (C) 2021 Imoisi et al. This is an open access article distributed under the Creative Commons Attribution License (CCL), which permits unrestricted use, distribution, and reproduction in any medium, provided the original work is properly cited.

Dates: Received: 10 May 2021; Revised: 28 June 2021; Accepted: 01 July 2021

Keywords: Edible oil, lipid profile, Albino rats, Cholesterol, Hypercholesteama

Consumption of fats and oils have been linked to high hypercholesteama in the body, diabetes and heart diseases, Consumers need meaningful information to enable them make informed choices of their diets and the types of oil they purchase and consume. The trend toward the consumption of healthier foods has stimulated the search for alternative oils or methods for improving the quality of oils presently used in food processing. This has led to the modification of naturally occurring oils to meet carefully designed specifications. Improved edible oils can be produced by physically blending oils in order to modify their properties and improve the oil functionality and meet product specifications. Blending of oils serves to improve and enhanced the nutritional quality of the oils. Thereby improving commercial viability (Abdulkarim et al; 2010b). Blending of oils physically modifies fatty acid distribution without any chemical or biological process (Liu and White, 1992). The food value of the oils and blends can also be predetermined to provide the safest food for consumers (Bazlul et al; 2010). Palm olein is considered as the gold standard in frying and is perhaps, on its own, the most widely used frying oil in the world (Grasas, 2010). Palm kernel oil has a low health rating because it is high in saturated fatty acids and low in essential fatty acids, making it a poor addition to the diet. Palm kernel oil is cheap and readily available in many regions, making it an economically attractive alternative to the healthier palm oil. Palm kernel oil is typically solid at room temperature, and it can withstand very high temperatures. In parts of Africa and Asia, it is commonly used as cooking oil, but it can also be used in the production of soaps and cosmetics. Many cosmetics manufacturers utilize palm kernel oil as an inexpensive substitute for commodities or components like coconut oil and shea butter. The objective of this study is to determine the effects of palm oil, palm olein, palm kernel oil and their blends of blended oils on the lipid profile of Albino rats.

\section{MATERIALS AND METHODS}

Sample collection: The oils used for this studies were refined, bleached and deodourized palm olein, crude palm oil and crude palm kernel oil. Samples were obtained from PRESCO Nig, Plc. Benin- City, Nigeria.

Preparation of blend: Palm olein and palm kernel oil were mixed in proportions ranging from $100 \%$ palm kernel oil to $100 \%$ palm olein in $20 \%$ increment 
(vol/vol). A total of four blends were prepared. Palm oil was not blended.

Animal and Toxicology studies: A total of seventyfive albino rats were procured. They were kept in ambient temperature, light / dark cycle of 12/12hours and supplied with feed and water ad libitum. They were then divided into 25 groups (three per group), including control.

Grand grower mesh pellets were used mixed with the various oils (i.e $10 \%$ of the oils were mixed with weighed amounts of pellets). Weekly body weight of each animal was assessed using weighing balance during the acclimatization period, once before the commencement of addition of $10 \%$ oil and subsequently once weekly when oil and the feeds had been mixed, i.e; during the dosing period and once on the day of sacrifice. At the end of the feeding period, the animals were fasted overnight, anaesthetized with chloroform and blood samples collected in plain tubes. Before sacrifice the rats were kept for 12 weeks.

Preparation of serum: Blood was collected from each of the rats by cardiac puncture into plain tubes, followed by centrifugation at 2,000rpm for $10 \mathrm{mins}$ using (Centrifuge 80-2 Techmel \& Techmel USA). Clear serum was collected separately for each sample with help of a syringe.

Biochemical analysis: Serum was used in determination of lipid profile using Randox Laboratories (England) kit according to manufacturer's instruction.

Determination of Total Cholesterol: Total cholesterol was determined according to the method of Reiser $e t$ al., (2013).

Determination of High Density Lipoprotein Cholesterol: High Density Lipoprotein Cholesterol was determined according to the method of LopesVirella (1997).

Determination of Total Triglyceride: Determination of Total Triglyceride was determined according to the method of Tietz (1990).

Determination of Low Density Lipoprotein Cholesterol: Low density lipoprotein was calculated according to Hlais et al (2013) and European Atherscierosis Society (1987).

Determination of Very Low Density Cholesterol: This was calculated according to the formula of Martin et al., (2013).
Statistical Analysis were carried out using one way analysis of variance (ANOVA) mean $\mathrm{P}<0.05$ was considered significant.

\section{RESULTS AND DISCUSSION}

High density lipoprotein cholesterol levels: HDL-C is considered "good cholesterol" because it assists in keeping arteries clear of deposits or plaque. They take out the low density lipoprotein cholesterol (LDL-C). They help to maintain free blood circulation. It gives some protection toward coronary heart illness. The HDL-C values obtained in this study from the serum of the animals was $(63.91 \mathrm{mg} / \mathrm{dl})$ for unheated palm olein, unheated palm oil gave value of HDL-C of $(59.13 \mathrm{mg} / \mathrm{dl})$ and PKO gave value of $(85.38 \mathrm{mg} / \mathrm{dl})$. The HDL-C was significant between and within groups at $(\mathrm{P} \leq 0.05)$ and statistically the same with the control. The HDL-C value obtained for palm oil is in agreement with the observation that palm oil fortified diets resulted in lower serum cholesterol level and compares favourably with corn oil and lightly hydrogenated soybean than saturated oil. Palm oil reduced the HDL-C concentrations in the rats.

PKO induced increase of the TC: HDL-C ratio indicates that it promoted the formation of more cholesterol than phospholipids (Nelson and Cox, 2000; Glew, 2006). These results probably indicate that PKO could promote the formation of more cholesterol and less phospholipid. Glew (2006) also reported that phospholipids expectially phosphatidycholine, had detergent properties in bile and aided in solubilizing cholesterol. LDL-C: HDL-C ratio supports the formation of more cholesterol.

Palm oil stimulates the synthesis of protective HDL-C and removal of harmful low density lipoprotein (LDLC) and has potent anti-oxidant effects. Palm oil is rich in vitamine $\mathrm{E}$ (particularly tocotrienols, carotene and tocopherols), which appear to reduce cholesterol concentration (Ebong et al; 1999). These antioxidants have also been proven to fight tumor cells (Steinbrecher, 1984) and inhibit cholesterol biosynthesis (Qureshi, 1986). The HDL-C values in this study falls within the range of $40-59 \mathrm{mg} / \mathrm{dl}$. However, the American Association for Clinical Chemistry has advised that levels higher than $70 \mathrm{mg} / \mathrm{dl}$ is beneficial. It gives protection against coronary heart diseases. Value obtained in this study was higher than $40 \mathrm{mg} / \mathrm{dl}$, the higher the value the better.

Low density lipoprotein cholesterol levels: LDL-C level of Albino rats were significantly the same between and within groups and controls at $(\mathrm{P} \leq$ 0.05).The test for low density lipoprotein cholesterol (LDL-C) is used as component of a lipid profile that is 
useful to predict an individual's risk of developing heart diseases. All forms of cholesterol in the blood; the LDL cholesterol build up can lead to blockage in the arteries because the LDL cholesterol is considered the most important form in determining risk factor of heart disease. Most treatment decision is often based on LDL values.

Table 1: Lipid profiles of oil samples $(\mathrm{mg} / \mathrm{dl})$

\begin{tabular}{|c|c|c|c|c|c|c|}
\hline $\begin{array}{l}\text { Feeds formulated } \\
\text { with oil }\end{array}$ & $\begin{array}{l}\text { Time } \\
\text { (mins) }\end{array}$ & Triglyceride & Total cholesterol & HDL-C & LDL-C & VLDL-C \\
\hline POL:PKO & 20 & $128.04 \pm 77.32^{2}$ & $197.90 \pm 19.87^{6}$ & $93.15 \pm 104.65^{2}$ & $79.14 \pm 15.89^{2}$ & $25.61 \pm 21.06^{2}$ \\
\hline \multirow[t]{2}{*}{$(80-20)$} & 40 & $107.50 \pm 98.37^{2}$ & $136.76 \pm 35.69^{2 \mathrm{~b}}$ & $61.92 \pm 43.87^{\circ}$ & $53.34 \pm 38.30^{\circ}$ & $21.50 \pm 22.64^{\circ}$ \\
\hline & 60 & $145.85 \pm 75.03^{2}$ & $204.77 \pm 75.31^{\text {th }}$ & $98.72 \pm 22.94^{\circ}$ & $76.88 \pm 75.77^{\circ}$ & $29.17 \pm 23.40^{\circ}$ \\
\hline POL:PKO & 20 & $110.00 \pm 44.48^{x}$ & $196.86 \pm 125.03^{a b}$ & $91.23 \pm 43.43^{\circ}$ & $83.63 \pm 98.17^{\circ}$ & $22.00 \pm 14.69^{\circ}$ \\
\hline \multirow[t]{2}{*}{$(60: 40)$} & 40 & $130.80 \pm 11.40^{2}$ & $183.62 \pm 11.80^{2 t}$ & $82.30 \pm 9.07^{2}$ & $75.16 \pm 8.67^{2}$ & $26.16 \pm 19.11^{\circ}$ \\
\hline & 60 & $139.78 \pm 78.82^{2}$ & $178.23 \pm 60.35^{\text {t }}$ & $85.34 \pm 22.33^{\circ}$ & $64.93 \pm 75.06^{\circ}$ & $27.96 \pm 19.29^{\circ}$ \\
\hline \multirow[t]{3}{*}{ POL unblended } & 20 & $101.42 \pm 80.80^{2}$ & $122.74 \pm 35.04^{\text {sh }}$ & $55.37 \pm 16.56^{\circ}$ & $47.09 \pm 9.16^{2}$ & $20.28 \pm 12.58^{\circ}$ \\
\hline & 40 & $120.67 \pm 73.20^{2}$ & $140.44 \pm 30.93^{\mathrm{b}}$ & $60.95 \pm 13.45^{2}$ & $55.35 \pm 16.56^{\circ}$ & $24.13 \pm 18.33^{\circ}$ \\
\hline & 60 & $166.91 \pm 5053^{2}$ & $200.00 \pm 79.57^{\text {st }}$ & $84.83 \pm 10.97^{\circ}$ & $81.35 \pm 18.49^{\circ}$ & $33.82 \pm 41.22^{2}$ \\
\hline PKO-POL & 20 & $160.50 \pm 6015^{2}$ & $235.41 \pm 27.83^{\text {s }}$ & $132.55 \pm 77.55^{2}$ & $70.76 \pm 34.14^{=}$ & $32.10 \pm 22.49^{\circ}$ \\
\hline \multirow[t]{2}{*}{$(80: 20)$} & 40 & $183.34 \pm 124.04^{2}$ & $230.12 \pm 91.64^{2}$ & $111.00 \pm 15.56^{2}$ & $82.45 \pm 33.80^{\circ}$ & $36.67 \pm 16.17^{\circ}$ \\
\hline & 60 & $195.06 \pm 56.50^{\mathrm{a}}$ & $243.12 \pm 13.24^{\text {st }}$ & $100.09 \pm 17.99^{2}$ & $104.02 \pm 34.14^{2}$ & $39.01 \pm 33.53^{\circ}$ \\
\hline POL & 20 & $170.88 \pm 61.10^{2}$ & $210.00 \pm 10.66^{b}$ & $91.50 \pm 13.45^{\circ}$ & $84.32 \pm 22.81 a$ & $34.18 \pm 12.90^{\circ}$ \\
\hline \multirow[t]{2}{*}{$(60: 40)$} & 40 & $3 \pm 73.93^{2}$ & $215.29 \pm 21.02^{2 b}$ & $101.00 \pm 10.97^{2}$ & $79.47 \pm 37.90 \mathrm{a}$ & $34.82 \pm 2.05^{2}$ \\
\hline & 60 & $180.33 \pm 16.75^{2}$ & $233.52 \pm 49.21^{\text {s }}$ & $110.00 \pm 77.55^{2}$ & $87.45 \pm 19.02 \mathrm{a}$ & $36.07 \pm 9.91^{2}$ \\
\hline \multirow[t]{3}{*}{ PKO unblended } & 20 & $150.62 \pm 58.25^{2}$ & $180.02 \pm 10.43^{\text {sh }}$ & $66.97 \pm 9.02^{2}$ & $82.93 \pm 53.10^{\circ}$ & $30.12 \pm 10.98^{\circ}$ \\
\hline & 40 & $166.78 \pm 27.02^{2}$ & $197.65 \pm 88.65^{\mathrm{s}}$ & $78.44 \pm 8.41^{2}$ & $85.85 \pm 23.23^{\circ}$ & $33.36 \pm 25.33^{\circ}$ \\
\hline & 60 & $180.40 \pm 92.43^{2}$ & $220.03 \pm 95.76^{\text {tb }}$ & $89.23 \pm 17.85^{\circ}$ & $94.72 \pm 37.90^{\circ}$ & $36.08 \pm 19.40^{\circ}$ \\
\hline \multirow[t]{3}{*}{ PO unblended } & 20 & $112.29 \pm 44.35^{\mathrm{a}}$ & $140.08 \pm 12.28^{2 b}$ & $63.92 \pm 16.03^{2}$ & $51.70 \pm 34.14^{=}$ & $22.46 \pm 27.43^{\circ}$ \\
\hline & 40 & $120.89 \pm 91.69^{2}$ & $151.46 \pm 63.59^{b}$ & $71.38 \pm 18.72^{2}$ & $55.90 \pm 38.34^{=}$ & $24.18 \pm 18.50^{\circ}$ \\
\hline & 60 & $130.41 \pm 53.64^{2}$ & $165.04 \pm 75.79^{2}$ & $78.95 \pm 22.39^{\circ}$ & $60.01 \pm 25.36^{\circ}$ & $26.08 \pm 19.05^{\circ}$ \\
\hline PO unheated & & $104.45 \pm 26.79^{\mathrm{a}}$ & $123.00 \pm 12.28^{\mathrm{sb}}$ & $59.13 \pm 16.46^{2}$ & $43.04 \pm 23.54^{=}$ & $20.83 \pm 3.99^{2}$ \\
\hline POL unheated & & $100.00 \pm 17.71^{2}$ & $120.26 \pm 63.59^{\mathrm{s}}$ & $63.91 \pm 43.84^{\circ}$ & $36.35 \pm 13.45^{\circ}$ & $20.00 \pm 15.16^{\circ}$ \\
\hline PKO unheated & & $142.53 \pm 118.52^{2}$ & $160.62 \pm 75.79^{25}$ & $75.38 \pm 27.59^{\circ}$ & $56.74 \pm 22.81^{=}$ & $28.51 \pm 3.49^{2}$ \\
\hline Control & & $203.96 \pm 167.64^{2}$ & $161.46 \pm 65.81^{\text {tb }}$ & $63.89 \pm 9.91^{2}$ & $76.53 \pm 48.72^{2}$ & $40.79 \pm 33.53^{\circ}$ \\
\hline
\end{tabular}

The control is the grand cereal feeds without the oil. The same superscript means it is not significantly different at $P \leq 0.05$. While different superscript is significantly different at $p<0.05$. LDL-cholesterol, VLDL-Cholesterol, triglycerides and HDL-cholesterol levels were all found to be significant at $(P \leq 0.05)$ between groups and within groups. Total cholesterol was significantly different at $p<0.05$.

Elevated levels of LDL cholesterol can indicate risk for heart disease, so an LDL-C result is evaluated with respect to the upper limits against a desired baseline. High LDL-C has the probability of inducing a cardiac arrest, since it triggers by building upon arterial blood vessels when very high. The outcome is a reduction of the circulation of blood and increase risk of cardiovascular illness and stroke. LDL $-\mathrm{C}$ levels are therefore, the very best gauge of the risk of cardiac arrest. In all the plasma samples analysed only that for PKO: POL (80:20) heated at $200^{\circ} \mathrm{C}$ for 60 mins rose to $104 \mathrm{mg} / \mathrm{dl}$. This was however, within the range of 100 $129 \mathrm{mg} / \mathrm{dl}$ which is considered near optimal or close to ideal (AACC, 2015). LDL-C values of PKO therefore indicate the likely harmful effect of PKO. The highest level of cholesterol was recorded in Albino rats that were fed feeds containing PKO. The Present results confirmed those of Bolanle and Dais (2007), who concluded that dietary intake of PKO on a long term basis could pose a risk of coronary heart disease and also confirmed the joint FAO/WHO expert consultation report which stated that lauric $(\mathrm{C} 12.0)$, myristic (C14.0) and palmitic acid (C16.0) consumption caused an increase in LDL-C whereas stearic acid (C18.0) had no effect on LDL-C and replacing saturated fatty acids (C12.0-C16.0) with unsaturated fatty acids decreased both LDL-C concentration and the total cholesterol / HDL-C ratio.

Total Triglyceride Cholesterol levels: Triglycerides (TG) are another form of fat in the blood that can raise the risk of heart disease. They are derived from our diets. Every ingested calorie not required by the body is transformed into triglycerides which are deposited in the body in the form of fat. Table 1 showed that feeding Albino rats on feeds containing palm kernel oil increased triglyceride levels significantly. The TG was significant between and within groups at $(\mathrm{P} \leq 0.05)$. It was raised in feeds fortified with blends of PKO and heated PKO. The ideal level of triglycerides should be lower than $150 \mathrm{mg} / \mathrm{dl}$ (AACC, 2015) and the total triglyceride cholesterol level of rats whose feeds were formulated with PKO fell within the borderline of 150 - 199mg/dl (AACC, 2015).

Total cholesterol levels: Total cholesterol levels was similar to control, between and within groups; at $(\mathrm{P} \leq$ $0.05)$, no significant difference was observed. This measures the total amount of cholesterol in blood, including LDL-C and HDL-C. Table 1 shows that 
feeding rats on feeds containing palm kernel oil increased significantly the total cholesterol level of Albino rats compared with those that were fed diet containing POL and blends of POL, with the same level of oil. Most of the plasma cholesterol levels were less than $200 \mathrm{mg} / \mathrm{dl}$ which is considered desirable (AACC; 2015) while higher values were obtained for fortification of feeds with blends of PKO: POL (80:20) and (60:40), between 230-243mg/dl and 210$233 \mathrm{mg} / \mathrm{dl}$ respectively. Total cholesterol level of 200$239 \mathrm{mg} / \mathrm{dl}$ is considered borderline high. While $240 \mathrm{mg} / \mathrm{dl}$ and above is considered high.

Very low density lipoprotein levels: VLD-cholesterol levels were similar with control, between and within groups at $(\mathrm{P} \leq 0.05)$ and no significant difference was observed. It is produced in the liver and released into the bloodstream to supply body tissues with triglycerides. About $50 \%$ of a VLDL particle is made up of triglycerides. High levels of VLDL cholesterol have been associated with the development of plaque deposits on artery walls, which narrows the passage and restrict blood flow with consequent elevation of blood pressures. VLDL cholesterol is termed bad cholesterol. It helps cholesterol build up on the walls of arteries. Table 1 showed that feeding rats on feeds containing palm kernel oil increased significantly VLDL-C level compared with those of rats that were fed diet containing POL and blends of POL at the same level of oil. PKO for treated, untreated and blended samples showed marginal increase in VLDL-C. The VLDL cholesterol value obtained in this study for untreated, treated and blended oil fortified feeds fed to rats, was within the range of VLDL cholesterol (AACC, 2015). However, samples of feeds including PKO and blends of PKO were higher and all above the recommended limit of $2-30 \mathrm{mg} / \mathrm{dl}$ for VLDL cholesterol.

Conclusion: This study shows that oils can be blended by blending saturated oils with unsaturated ones, thereby, modifying the properties of the oils such as (Blending palm olein and palm kernel oil). Palm oil being rich in antioxidant reduced total cholesterol concentration by stimulating the synthesis of protective high density lipoprotein cholesterol and lowering harmful low density lipoprotein cholesterol. Dietary intake of palm kernel oil on a long term basis could pose a risk of coronary heart disease. Palm kernel oil helps to lower HDL-C and reduces total triglyceride, total cholesterol level.

\section{REFERENCES}

AbdulKarim, SM., Myat, MW; Ghazali, HM. (2010b). Sensory and Physicochemical Qualities of Palm
Olein and Sesame Seed Oil Blends during Frying of Banana Chips, J. Agri. Sci. 2(4), 18-29

Bazlul, MS., Anees, A., Mohamad, HI, Sufia, H., Mohd Rafatullah; Mohd Omar, AK (2010): Physico-chemical properties of blends of palm olein with other vegetable oils, Grasas Y aceites, 61, 423-429.

Liu, H. And White, PJ. (1992): Oxidative stability of soybean oils with altered fatty acid composition. $J$. Am. Oil Chem. Soc. 69,528-532.

Lopes-Virella, MF., Stone, P., Ellis, S. and Colwell, JA. (1997): Cholesterol determination in high density lipoprotein separated by three different methods. 23, 882-884.

Tietz, NW. (1990): Clinical guide to laboratory test, Second Edition W.B. Saunders Company, Philadelphia, U.S.A. 554-556.

Hlais, S., El-Bistami, D., El-Rahi, B., Mattar, MA; Obeid, O.A. (2013): Combined fish oil and high oleic sunflower oil supplements neutralize their individual effects on the lipid profile of healthy men. Pubmed J. 48(9): 853-61.

European Atherscierosis Society (1987). Martin, SS., Blaha, MJ; Elshazly, MB. (2013): Friedewaldestimated versus directly measured low density lipoprotein cholesterol and treatment implications. J. Am. Coll Cardiol. 62(8): 732-739.

Nelsin, MC. and Cox, DL. (2000): Lehninger Principles of Biochemistry, $3^{\text {rd }}$ edition Worth Publishers.

Glew, RH. (2006): Lipid metabolism11: pathways of metabolism of special lipids in textbook of Biochemistry with clinical correlations, Devlin, T.M. (Ed). $6^{\text {th }}$ Edn. Wiley U.S.A; New Jersey, pp: 695-741.

Ebong, PE., Owu, DU. and Isong, EU. (1999): Influence of palm oil (Elaesis guineensis) on health. J. Plant Foods Hum. Nutri 53(3): 209-222

Younis Talpur, M. Sherazi, STH. Mahesar, SA. Bhanger, MI. Aftab Kandhro (2011).Consequence of commercial fish frying on some quality parameters of oil with special reference to trans-fat. Int. J. Food Props, 14, 1124-1135

Faranak K., Manochehr, B., Majid, A. and Elisan, S. (2010): Effect of vegetable oil oxidation on the 
hydrogenation reaction process. Grasas Y.A ceites 61(4)

Steinbrecher,UP., Parthasarathy,S., Leake, DS., Witztum, J.L. and Steinberg, D. (1984): Modification of low density lipoprotein by endothelial cells involves lipid peroxidation and degradation of low density lipoprotein phospholipids. Proc. Natl. Sci. U.S.A. A81:38823887.

Qureshi, AA; Burger, WC; Peterson, DA and Elson, CE. (1986): The structure of an inhibitor of cholesterol biosynthesis isolated from barley. J.Biol.Chem.261. 10544-10550.
Rajagopal, G; Suresh, V. and Sachan, A. (2012): High density lipoprotein cholesterol: How high. Indian J. Endocrinol Metab. (Suppl 2) 2230-8210

FAO/WHO (1992). Joint report on expert consultation, Rome. In: Fats and Oils in Human Nutrition.

FDA (1986): Federal Register 51 (227), 42593-42593, Food and Drug Administration, USA. 